\title{
A house of cards: women, aging and spinal cord injury
}

Since the early 1980's, long-term survivors of spinal cord injury have been sharing their stories with us, helping us to understand what it means to spend one's adult life with a spinal cord injury. Quantitative and qualitative research has contributed to an impressive storehouse of knowledge about the dynamic nature of spinal cord injury over the lifespan. ${ }^{1,2}$ In the last five years in particular, increasingly precise and definitive information has helped us understand, explain, and perhaps even predict expectations associated with age. $^{3-6}$

As a number of authors correctly point out, given the demographics of spinal cord injury, samples for this research have tended to contain a majority of men. However, recent epidemiological information shows that incidence has increased in women over 60 , such that the etiological distribution is now bimodal-highest among young men and older women. ${ }^{7-11}$ It stands to reason that the issues of older women with spinal cord injuries would be different from those of older men, most of whom have lived with their injury since their 20's or 30's. Besides the obvious effects of gender on aging and agerelated concerns, duration of disability is also an issue. A clear relationship has been shown between duration of disability and a number of important aging outcomes, particularly psychological outcomes and overuse syndromes. ${ }^{12,13}$ It appears that the longer one lives with the injury, the greater the toll it exacts physically, yet paradoxically, the more life satisfaction and quality of life survivors report.

What then are the main issues for women aging with spinal cord injuries, and also for those who seek to provide service or information to them? I propose to briefly summarize the key issues raised by the research (physical/medical, psychological, social and environmental), ${ }^{14}$ focussing particularly on the most recent findings.

In the category of physical/medical issues, the primary concern, and by far the most dominant issue in the literature, is osteoporosis. Changes in bone mineral density that occur naturally with age are compounded by spinal cord injury and decreased weight-bearing, placing women with spinal cord injuries at exponentially increased risk of fractures. $^{15-19}$ Interestingly, however, bone mineral density in the spine was either maintained or increased among women with spinal cord injuries, making them less likely than women in the general population to experience postural deformities with age. $^{20}$

A second issue in the physical/medical category is post-reproductive gynaecological concerns, particularly menopause. On balance, the research appears to suggest that the experience of menopause is similar for able-bodied and disabled women. ${ }^{21,22}$ However, there are a number of complicating factors for women with disabilities, such as the exaggerated impact of surgery/ hysterectomy for someone with a pre-existing disability and the necessity of distinguishing between menopausal and other symptoms (eg., hot flushes and autonomic dysreflexia). ${ }^{23}$

Two final concerns in this category are bladder functioning and weight. Bladder function, incontinence and urinary tract infections become worse with age among women in the general population, and particularly among women with spinal cord injuries. ${ }^{22-24}$ To fully understand the importance of bladder complications, they must be seen against the background of possibly years of antibiotic use, sedentary posture, and limited treatment options.

Body composition of women with spinal cord injuries has been characterized as a deficiency of protein and bone mass, and an excess of fat. ${ }^{17}$ For all women, these same three trends increase with age, however for women with spinal cord injuries, they pose particular difficulties with transfers, risk of fractures and potential for skin breakdown. ${ }^{26,27}$

In the category of psychological complications for women aging with a spinal cord injury, depression is the most significant issue raised in the literature. The co-incidence of three risk factors (age, gender and disability) results in an excess of depression among older women with spinal cord injuries. ${ }^{3,28,29}$ Furthermore, whereas research shows that psychological outcomes improve after 30 years duration of disability, ${ }^{12}$ women injured at the modal age of 60 are unlikely to enjoy this benefit.

The literature raises three social issues for older disabled women, including caregiving issues, employment/finances and transportation. Higher rates of divorce, separation, and remaining single among women with disabilities means that they are more likely than men to receive personal care from an attendant. ${ }^{11,30,31}$ Although exchanging personal care within an intimate relationship has its own complications, so too does the necessity of hiring, training, supervising and retaining attendants. ${ }^{32,33}$ 
The research shows that women are less likely than men to be employed after their injury, ${ }^{34}$ and thus more likely to be dependent on social welfare for their income. As a result, many live substantially in poverty, with little opportunity for improving their financial security. ${ }^{11}$ When this is combined with divorce, single parenthood and aging, the picture becomes discouraging indeed.

Third, researchers have observed that women with spinal cord injuries are significantly less likely than men to be independent in their use of transportation. ${ }^{11}$ This finding would not seem so important had not older men with spinal cord injuries repeatedly and emphatically told us how much the use of their vehicle contributed to their autonomy and quality of life. ${ }^{35}$

Finally, in the category of environmental complications for women aging with a spinal cord injury, the most frequently mentioned were barriers to access to health services, particularly primary and preventive services. While people with disabilities generally have difficulty accessing primary care ${ }^{36-38}$ the literature shows that women are particularly disadvantaged in terms of routine preventive measures, such as Pap smears, pelvic exams and mammograms. ${ }^{21}$ The discrepancy increases with severity of disability, ${ }^{39}$ and appears to be related to three types of barriers-physical inaccessibility, attitudes of professionals and lack of expertise about disability. ${ }^{40-42}$ In the absence of primary and preventive care, women with spinal cord injuries lack a first line of defense for maintaining the sometimes fragile balance of their health. ${ }^{14,26}$

In summary, the literature raises a number of specific issues and concerns for women aging with a spinal cord injury. Perhaps most troubling about these are two factors: the difficulty both men and women with spinal cord injuries have obtaining informed primary care, ${ }^{36-38}$ and the known relationship between secondary complications and overall quality of life. ${ }^{14,43,44}$ Whereas the recent literature seems to suggest that men injured early in life may have had the opportunity to carve out a satisfying life after many years with the disability, ${ }^{12}$ women, often injured in their 60's, may be still adjusting to the original injury when additional age-related difficulties befall them. It is pointless to say that one situation is more advantageous or preferable-that having spent one's whole adult life with a disability is either better or worse than having to adjust to aging and spinal cord injury at the same time. The literature is clear that the spinal cord injury itself is more deterministic than gender of changes associated with aging. ${ }^{11}$ Further, it shows no significant differences in overall quality of life among men and women with spinal cord injuries. ${ }^{5,39}$

I am reminded of a metaphor used by one of the participants in our earlier qualitative research, who characterized living with a disability as a house of cards'-precariously balanced, but easily brought tumbling down, sometimes by the smallest perturbation. ${ }^{1}$ In order to fulfil the promise of recent encouraging projections about life expectancy, ${ }^{28,45}$ it is essential that accessible, informed health services are available to people with spinal cord injuries when secondary complications arise. To extend the 'house of cards' metaphor, primary care is needed that anticipates the possibility of a wobbly card, is alert to the first signs that the structure is becoming unstable, is aware of the dependency of the whole structure on each individual card, can re-establish the balance in a single card without disturbing those around it, and never gives up on the possibility of keeping the whole house intact.

\section{MA McColl \\ Queen's University, Centre for Health Services and Policy Research, \\ Kingston, ON, Canada K7L-3N6}

\section{References}

1 McColl MA, Rosenthal C, Rowe K. (1995) Aging with a disability: Consumer perspectives on handicap. In B. Pickles (ed.) Physiotherapy in the care and treatment of older adults. WB Saunders Ltd.

2 Whiteneck GG et al. Mortality, morbidity and psychosocial outcomes of persons spinal cord injured more than 20 years ago. Paraplegia 1992; 30: 616-630.

3 Bauman WA et al. Levels of plasma homocysteine in persons with spinal cord injury. J Spinal Cord Med 2001; 24: $81-86$.

4 Krause JS, Kemp B, Coker J. Depression after spinal cord injury: relation to gender, ethnicity, aging, and socioeconomic indicators. Arch Phys Med Rehabil 2000; 81: $1099-1109$.

5 McColl MA. Expectations of health, independence and quality of life among spinal cord injured adults. Assistive Technology 1999; 11: 130-136.

6 Charlifue SW, Weitzenkamp DA, Whiteneck GG. Longitudinal outcomes in spinal cord injury: Aging, secondary conditions, and well-being. Arch Phys Med Rehabil 1999; 80: $1429-1434$.

7 Chen HY et al. A nationwide epidemiological study of spinal cord injury in geriatric patients in Taiwan. Neuroepidemiology 1997; 16: 241 - 247.

$8 \mathrm{Hu}$ R, Mustard CA, Burns C. Epidemiology of incident spinal fracture in a complete population. Spine 1996; 21: $492-499$

9 Kannus P, Niemi S, Palvanen M, Parkkari J. Continuously increasing number and incidence of fall-induced, fracture-associated, spinal cord injuries in elderly persons. Arch Int Med 2000; 160: 2145-2149.

10 Nobunaga AI, Go BK, Karunas RB. Recent demographic and injury trends in people served by the Model Spinal Cord Injury Care Systems. Arch Phys Med Rehabil 1999; 80: $1372-1382$.

11 Shackelford M, Farley T, Vines CL. A comparison of women and men with spinal cord injury. Spinal Cord 1998; 36: $337-339$.

12 Krause JS. Aging and life adjustment after spinal cord injury. Spinal Cord 1998; 36: 320-328. 
13 Pentland W, McColl MA, Rosenthal C. The effect of aging and duration of disability on long-term health outcomes following spinal cord injury. Paraplegia 1995; 33: $367-373$.

14 Coyle CP et al. Secondary conditions and women with physical disabilities. Arch Phys Med Rehabil 2000; 81: $1380-1387$

15 Boling EP. Gender and osteoporosis: Similarities and sex-specific differences. Journal of Gender-specific Medicine 2001; 4: $36-43$.

16 Garland DE et al. Regional osteoporosis in women who have a complete spinal cord injury. Patient Care Management 2001; 83-A: 1195 - 1200.

17 Kocina P. Body composition of spinal cord injured adults. Sports Med 1997; 23: $48-60$.

18 Ott SM. Osteoporosis in women with spinal cord injuries. Physical Medicine \& Rehabilitation Clinics of North America 2001; 12: $111-131$.

19 Kiratli BJ et al. Bone mineral and geometric changes through the femur with immobilization due to spinal cord injury. J Rehabil Res Dev 2000; 37: 225-233.

20 DeLaet CE, Pols HA. Fractures in the elderly: Epidemiology and demography. Best Practice Research in Clinical Endocrinology \& Metabolism 2000; 14: 171 - 179.

21 Jackson AB, Wadley V. A multicenter study of women's self-reported reproductive health after spinal cord injury. Arch Phys Med Rehabil 1999; 80: 1420 - 1428.

22 Vanderakke CB, Glass DD. Menopause and aging with disability. Physical Medicine and Rehabilitation Clinics of North America 2001; 12: 133 - 151.

23 Mohyi D, Tabassi K, Simon J. Differential diagnosis of hot flashes. Maturitas 1997; 27: $203-214$.

24 Valiquette L. Urinary tract infections in women. Can $J$ Urol 2001; 8(Suppl 1): 6-12.

25 Yavuzer $\mathrm{G}$ et al. Compliance with bladder management in spinal cord injury patients. Spinal Cord 2000; 38: $762-$ 765.

26 Rimmer JH. Health promotion for people with disabilities: The emerging paradigm shift from disability prevention to prevention of secondary conditions. Phys Ther 1999; 79: 495-502.

27 Curtis KA et al. Shoulder pain in wheelchair users with tetraplegia and paraplegia. Arch Phys Med Rehabil 1999; 80: $453-457$.

28 Hartkopp A, Bronnum-Hansen H, Seidenschnur AM, Biering-Sorensen F. Suicide in a spinal cord injured population: its relation to functional status. Arch Phys Med Rehabil 1998; 79: 1356-1361.

29 Kennedy P, Rogers BA. Anxiety and depression after spinal cord injury: a longitudinal analysis. Arch Phys Med Rehabil 2000; 81: 932 - 937.
30 Kreuter M. Spinal cord injury and partner relationships. Spinal Cord 2000; 38: 2-6.

31 Krogh K, Nielsen J, Djurhuus JC, Mosdal C, Sabroe S, Laurberg S. Colorectal function in patients with spinal cord lesions. Dis Colon Rectum 1997; 40: 1233 - 1239.

32 Frazee C. Balance \& movement. In McColl MA, Bickenbach $\mathbf{J}$ (eds.) Introduction to Disability. London: WB. Saunders, 1998

33 McColl MA. Issues for caregivers of people aging with a spinal cord injury. In Mosqueda, L. \& Kemp, B. (eds.) Aging with a Disability. Baltimore, MD: Johns-Hopkins Press, 2001.

34 Krause JS et al. Employment after spinal cord injury: an analysis of cases from the Model Spinal Cord Injury Systems. Arch Phys Med Rehabil 1999; 80: 1492-1500.

35 McColl MA, Rosenthal C. A model of resource needs of aging spinal cord injured men. Paraplegia 1994; 32: $261-$ 270.

36 DeJong G. Primary care for persons with disabilities. An overview of the problem. Am J Phys Med Rehabil 1997; 76(Suppl 3): S2-S8.

37 Teasell R, Allatt D. Managing the growing number of spinal cord-injured elderly. Geriatrics 1991; 466: 83-85.

38 Francisco GE, Chae JC, DeLisa JA. Physiatry as a primary care specialty. Am J Phys Med Rehabil 1995; 74: $186-192$

39 Nosek MA, Howland CA. Breast and cervical cancer screening among women with physical disabilities. Arch Phys Med Rehabil 1997; 78(12 Suppl 5): S39-S44.

40 Becker H, Stuifbergen A, Tinkle M. Reproductive health care experiences of women with physical disabilities: A qualitative study. Arch Phys Med Rehabil 1997; 78(12 Suppl 5): S26-S33.

41 Graham A, Savic G, Gardner B. Cervical and breast cancer screening in wheelchair dependent females. Spinal Cord 1998; 36: 340-344.

42 Heath GW, Fentem PH. Physical activity among persons with disabilities - a public health perspective. Exerc Sport Sci Rev 1997; 25: 195-234.

43 Tate DG, Riley BB, Perna R, Roller S. Quality of life issues among women with physical disabilities or breast cancer. Arch Phys Med Rehabil 1997; 78(12 Suppl 5): $\mathrm{S} 18-\mathrm{S} 25$

44 Westgren N, Levi R. Quality of life and traumatic spinal cord injury. Arch Phys Med Rehabil 1998; 79: 14331439

45 McColl MA, Walker J, Stirling P, Wilkins R, Corey P. Expectations of life and health following spinal cord injury. Spinal Cord 1997; 35: 818-828. 